\title{
Transjugular Closure of Secundum Atrial Septal Defect in a Patient with Interrupted Inferior Vena Cava
}

\author{
Emre Ozdemir, Sadik Volkan Emren, Nihan Kahya Eren, Cem Nazli, Mehmet Tokac \\ Cardiology Clinic, Izmir Katip Celebi University, Ataturk Education and Research Hospital, Izmir, Turkey
}

\section{Abstract}

In this case, we report a successful closure of secundum atrial septal defect in a 32-year-old female patient with an interrupted inferior vena cava (IVC). Interrupted IVC was detected coincidentally during right heart catheterization. The defect was successfully closed through transjugular vein approach as an alternative to surgery.

Keywords: Amplatzer septal occluder device, inferior vena cava, jugular veins, ostium secundum atrial septal defect

\section{INTRODUCTION}

Atrial septal defect (ASD) is seen in $30 \%-33 \%$ of adults. Although ASD is usually asymptomatic, it can lead to exercise intolerance, atrial arrhythmia, right ventricular dysfunction, and pulmonary hypertension with aging and lifespan diminishes in adult patients with untreated large defects. As a potentially serious complication, the risk of developing pulmonary vascular disease is higher in adults with untreated defects. The main treatment option is transcatheter closure which is less invasive and more comfortable for patients. Percutaneous closure is routinely performed by the transfemoral route through inferior vena cava (IVC). However, operator rarely comes across unexpected vascular access problems such as interrupted IVC during the closure of ASD.

Congenital interrupted IVC with azygos continuation is a rare variation usually associated with other congenital anomalies. The incidence of this anomaly nearly $0.6 \%$ in patients with congenital heart defects additional to atrioventricular canal defect, anomalously connecting pulmonary veins, double outlet right ventricle, large ASD, pulmonary stenosis or atresia, and sick sinus syndrome. ${ }^{[1,2]}$ Usually, the presence of this vascular variation alone does not cause clinically problems, and it is found incidentally ${ }^{[3,4]}$ either during an examination or at postmortem dissection. However, in some cases, it can become clinically important.

\begin{tabular}{|l|l|}
\hline \multicolumn{3}{c|}{ Access this article online } \\
\hline Quick Response Code: & Website: \\
& http://www.ijcva.com \\
\cline { 2 - 2 } & \\
\end{tabular}

\section{Case Report}

A 32-year-old woman was admitted to our hospital with a complaint of dyspnea and palpitation. A fixed wide splitting of the second heart sound and a Grade 2/6 systolic murmur was auscultated at the second left intercostal space. Electrocardiogram was in sinus rhythm with an incomplete right bundle branch block. Transthoracic echocardiogram revealed mild right ventricular dilatation and secundum ASD. Transesophageal echocardiography (TEE) revealed a $12 \mathrm{~mm}$ secundum ASD with sufficient rhymes for percutaneous closure [Figure 1a]. Cardiac catherization was performed under general anesthesia using TEE. A 7-F sheath was placed through the right femoral vein. Afterward; despite many attempts, the guidewire could not be passed through IVC. Venography revealed interrupted IVC [Figure 1b] and venous flow reached to the right atrium through collaterals and azygos continuation of interrupted IVC to superior vena cava (SVC) [Figure 1c]. Because of the sharp angulation of azygous continuation at SVC, percutaneous ASD closure was decided to be continued through transjugular approach. A 7-F sheath was placed to the right internal jugular vein. The initial attempt to cross the interatrial septum with an

Address for correspondence: Dr. Emre Ozdemir, Celebi Cardiology Clinic, Katip Celebi University, Atatürk Education and Research Hospital, Izmir, Turkey. E-mail: emreozdemir27@yahoo.com.tr

This is an open access journal, and articles are distributed under the terms of the Creative Commons Attribution-NonCommercial-ShareAlike 4.0 License, which allows others to remix, tweak, and build upon the work non-commercially, as long as appropriate credit is given and the new creations are licensed under the identical terms.

For reprints contact: reprints@medknow.com

How to cite this article: Ozdemir E, Emren SV, Eren NK, Nazli C, Tokac M. Transjugular closure of secundum atrial septal defect in a patient with interrupted inferior vena cava. Int J Cardiovasc Acad 2018;4:15-8. 


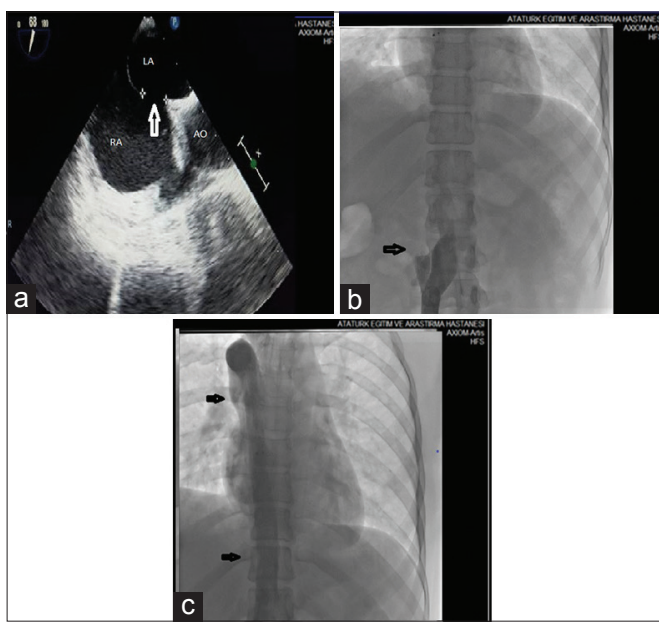

Figure 1: (a) Transesophageal appearance of the secundum atrial septal occluder before closure (white arrow), (b) Interrupted section of inferior vena cava, (c) The azygos continuation of interrupted inferior vena cava

6-F Multipurpose catheter was unsuccessful. In the next attempt, the tip of a Cobra $\left(\right.$ Terumo $\left.^{\circledR}\right)$ catheter was well oriented to the ASD and the catheter could be easily passed into the left atrium (LA) over a 0.35 j-tipped guidewire. Then, the $0.35 \mathrm{j}$-tipped guidewire was exchanged with a super stiff 0.38 -inch guidewire which is placed in the left upper pulmonary vein. Afterward, an ASD sizing balloon was passed through the ASD over the stiff guidewire; however, with the introducement of the catheter of the sizing balloon, the stiff wire was displaced from the upper pulmonary vein. Therefore, the stiff wire was relocated into the left lower pulmonary vein where it was more stable and could better carry the sizing balloon catheter. The defect was measured $12 \mathrm{~mm}$ with the sizing balloon. After balloon sizing, an $8 \mathrm{~F}$ Amplatzer $^{\circledR}$ delivery system (St. Jude Medical, St Paul, MN, USA) was introduced through the internal jugular vein. While negotiating the delivery system, the stiff wire was displaced from the lower pulmonary vein and fell into the left ventricular cavity [Figure 2a]. The delivery sheath and its dilator were gently advanced over the stiff wire until the sheath was placed in the left ventricular cavity. The stiff wire and dilator were removed from the delivery sheath while maintaining the tip of the sheath within the left ventricle. Under fluoroscopic guidance, a 14-mm Amplatzer ${ }^{\circledR}$ atrial septal occluder (ASO) (St. Jude Medical, St Paul, MN, USA) device was passed through the delivery catheter without exiting from the tip of the sheath [Figure 2b]. Then, the whole system was withdrawn into the left atrial cavity and the tip of sheath was placed above the mitral valve under TEE guidance. Left disc of the device was unsheated within the LA and gently pulled against the interatrial septum. Using gentle tension on the delivery system, the sheath was pulled back, and the right atrial disc was opened [Figure 2c and d] Subsequent Minnesota maneuver of the delivery system ensured a safe device positioning across the ASD. Finally, the delivery system was unlocked, and device was released [Figure 2e]. Control TEE demonstrated

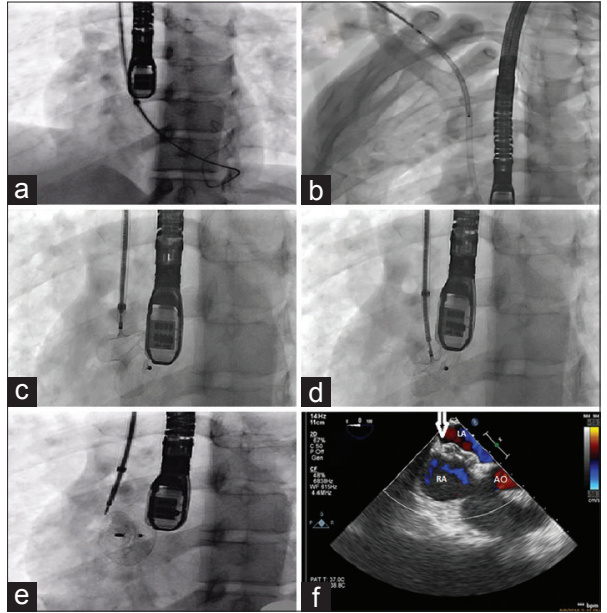

Figure 2: Transesophageal echocardiography and fluoroscopy-guided closure steps through internal jugular approach: (a) stiff wire in the left ventricle (b) atrial septal occluder device within the delivery system, tip of the delivery catheter is in the left ventricle (c and d) opening steps of the right atrial disc (e) released atrial septal occluder device (f) Cessation of the interatrial shunt (white arrow: atrial septal occluder device, RA: Right atrium, LA: Left atrium, A0: Aortic valve)

a stable occluder device with cessation of the interatrial shunt [Figure 2f] and the procedure was completed without any complications.

\section{Discussion}

IVC is built of four segments during the embryonic progress and defect of the formation of hepatic segment. Interruption of the IVC with the continuation of azygos system represents the most common abnormality of these of embryonic veins. ${ }^{[4]}$ This malformation is a member to be a marker for the presence of atrial isomerism and the polysplenia syndromes. ${ }^{[5]}$ However, our patient had isolated secundum ASD and interrupted IVC without any other concomitant congenital abnormality. This finding can be important when an interventional procedure will be performed. The delivery systems for transcatheter closure are designed to be used from the femoral veins. However, there are some conditions impeding transfemoral venous approach such as IVC interruption. In these cases, transjugular, transhepatic approach, or surgery can be an alternative for closure. At some rare cases, transfemoral closure can be also possible through the azygos continuation of the interrupted IVC: ${ }^{[6,7]}$ however, in most cases, navigation of the with large caliber delivery sheaths through the azygous vein may be difficult and may result in vessel injury. Intrathoracic vein injuries can result in catastrophic hemorrhage, especially if the injury to the vein communicates with the pleural or mediastinal space. Because of the abrupt angulation of the azygous vein at its entry into the SVC, a stable guidewire and delivery sheath positioning may be extremely difficult as well as a proper sizing balloon placement. In suitable cases, transhepatic access can be used for percutaneous closure. This approach is particularly useful in infants, young children, and thin-built adults, in whom hepatic veins are larger than the 
jugular veins. In these patients, transhepatic method permits easier venous sheath placement and provides better catheter stability during the procedure ${ }^{[8]}$ On the other hand, transhepatic access may cause higher incidence of complications including retro or intraperitoneal bleeding, injury of the gallbladder, pneumothorax, pleural effusions, and liver abscess or peritonitis. ${ }^{[9]}$ As described previously in a few case reports, alternatively the transjugular approach is a potentially safer. Due to the previously explained difficulties, transjugular ASD closure has been reported only in two pediatric patients. ${ }^{[9,10]}$ On the other hand, review of the literature revealed 5 case reports of transjugular ASD closure in adult patients. ${ }^{[1-15]}$ These reports included patients with severe scoliosis, ${ }^{[13]}$ iatrogenic total occlusion of the IVC after an unsuccessful attempt with a CardioSEAL septal occluder, ${ }^{[14]}$ and postoperative residual ASD following surgical repair of total anomalous pulmonary venous connection. ${ }^{[15]}$ Transjugular ASD closure was reported in two adult patients with interrupted IVC, ${ }^{[11,12]}$ and the current case is the third similar case.

Transjugular approach for ASD closure is a relatively easier procedure in adults compared to the pediatric population. Due to the larger size of the internal jugular vein, venous puncture is easier and large caliber sheaths; delivery systems can be safely introduced in adult patients. Narin et al., reported the hematoma in the muscles of the neck that was caused transient loss of strength after the procedure. ${ }^{[10]}$ Such complication was not observed in our case and previous transjugular ASD closures in adult patients.

Transjugular approach has some minor procedural differences compared to the transfemoral closure. Passing through the defect with a catheter and placing the guidewire in the pulmonary vein may be more difficult than the transfemoral route. In transfemoral approach, a multipurpose catheter is usually used to cross the defect. In transjugular approach, a right judkins or cobra catheter can be preferred at this step since their tips are better directed toward the ASD ${ }^{[9,11]}$ Placing and maintaining the guidewire in the left upper or lower pulmonary veins may be more difficult than the transfemoral route. In transjugular approach, the tip of the delivery system tends to point toward the left ventricular inflow or left atrial appendage and the tip of the catheter may easily fall into the left ventricular cavity before or after the guidewire removal. Similar to the current case, Bhargava et al., have also demonstrated that the delivery sheath can be safely placed within the left ventricular cavity to provide good support for the ASO advancement through the catheter ${ }^{[11]}$ However, TEE monitoring is essential during the procedure to prevent injury of the mitral valve and subvalvular structures. Echocardiographic guidance needs to ensure the opening of the left atrial disc away from the mitral valves in the left atrial cavity.

In transjugular approach, complications are quite a few. Bleeding is the most probable complications due to carotid, subclavian, or vertebral artery injuries. Compressing of artery is more difficult when compared with femoral vein approach for controlling of bleeding. Other risk for the jugular approach is air embolism because of the upper position of the internal jugular vein from the level of the heart. The sheath manipulations must be performed under the level of the heart to avoid of air embolism. After removal of the dilator and guidewire, avoidance for wounding of the left atrial or left ventricular walls, the location of the delivery sheath tip should be in attention, and a good backflow from the catheter should be seen before the insertion of the occlusion device.

\section{ConcLusion}

In experienced centers, percutaneous closure of ASD through transjugular access is a safe, feasible, and effective procedure in adult patients with interrupted IVC. Meticulous TEE guidance is essential during delivery sheath and device manipulations.

\section{Declaration of patient consent}

The authors certify that they have obtained all appropriate patient consent forms. In the form the patient(s) has/have given his/her/their consent for his/her/their images and other clinical information to be reported in the journal. The patients understand that their names and initials will not be published and due efforts will be made to conceal their identity, but anonymity cannot be guaranteed.

\section{Financial support and sponsorship}

Nil.

\section{Conflicts of interest}

There are no conflicts of interest.

\section{RefERENCES}

1. Colak MC, Rahman A, Kocaturk H, Bayram E, Kocakoc E. Interrupted inferior vena cava and partial anomalous pulmonary venous return with atrial septal defect in a 38-year-old adult: A case report. Cases J 2009;2:7346.

2. Vijayvergiya R, Bhat MN, Kumar RM, Vivekanand SG, Grover A. Azygos continuation of interrupted inferior vena cava in association with sick sinus syndrome. Heart 2005;91:e26.

3. Wolfhard U, Splittgerber FH, Gocke P, Reidemeister JC. Bilateral inferior vena cava with azygos continuation but without congenital heart disease complicates routine venous cannulation for cardiopulmonary bypass in an adult. Thorac Cardiovasc Surg 1997;45:40-2.

4. Floyd GD, Nelson WP. Developmental interruption of the inferior vena cava with azygos and hemiazygos substitution. Unusual radiographic features. Radiology 1976;119:55-7.

5. Phoon CK, Villegas MD, Ursell PC, Silverman NH. Left atrial isomerism detected in fetal life. Am J Cardiol 1996;77:1083-8.

6. Kashour TS, Latroche B, Elhoury ME, Galal MO. Successful percutaneous closure of a secundum atrial septal defect through femoral approach in a patient with interrupted inferior vena cava. Congenit Heart Dis 2010;5:620-3.

7. Lowry AW, Pignatelli RH, Justino H. Percutaneous atrial septal defect closure in a child with interrupted inferior vena cava: Successful femoral venous approach. Catheter Cardiovasc Interv 2011;78:590-3.

8. Sadiq N. Transhepatic approach for device closure of secundum atrial septal defect in patient with interrupted inferior vena cava. Cardiol Pharmacol 2014;3:120.

9. Ozbarlas N, Kiziltas A, Kucukosmanoglu O, Erdem S. Transjugular approach to device closure of atrial septal defect in a child with heterotaxia and interrupted inferior vena cava. Tex Heart Inst J 2012;39:435-7. 
10. Narin N, Pamukcu O, Baykan A, Argun M, Ozyurt A, Uzum K, et al. Percutaneous atrial septal defect closure by using jugular venous access in a case with interrupted inferior vena cava. Postepy Kardiol Interwencyjnej 2014;10:267-9.

11. Bhargava RA, Phatarpekar A, Lanjewar CP, Kerkar PG. Modified transjugular approach for percutaneous atrial septal defect closure. Ann Pediatr Cardiol 2017;10:197-9.

12. Seshagiri RD, Patnaik AN, Srinivas B. Percutaneous closure of atrial septal defect via transjugular approach with blockaid device in a patient with interrupted inferior vena cava. Cardiovasc Interv Ther 2013;28:63-5.

13. Abdel-Massih T, Boudjemline Y, Agnoletti G, Acar P, Iserin F,
Douste-Blazy MY, et al. Percutaneous closure of an interatrial communication via the internal jugular route using an Amplatzer prosthesis. Arch Mal Coeur Vaiss 2002;95:959-61.

14. Sullebarger JT, Sayad D, Gerber L, Ettedgui J, Jimmo-Waumans S, Alcebo PC, et al. Percutaneous closure of atrial septal defect via transjugular approach with the amplatzer septal occluder after unsuccessful attempt using the CardioSEAL device. Catheter Cardiovasc Interv 2004;62:262-5.

15. Mahesh Kumar S, Bijulal S, Krishnamoorthy KM. Percutaneous transjugular device closure of postoperative residual atrial septal defect J Invasive Cardiol 2013;25:E78-80. 